\title{
Endoscopic removal of slow release oxycodone tablets in a case of voluntary acute poisoning
}

\author{
Sossio Serra, Stefano Geniere Nigra \\ Emergency Department, Maurizio Bufalini Hospital, Cesena (FC), Italy
}

\begin{abstract}
We describe a case of 83-years-old women admitted to the Emergency Department after massive ingestion of slow release Oxycodone pills for suicidal purpose. After gastric lavage only few tablets has been retrieved and Naloxone infusion was necessary. After 2 hours from drug ingestion Esophagogastroduodenoscopy (EGDS) was performed and a number of tablets have been removed. Intoxication symptoms completely resolved and Naloxone infusion has been stopped. The clinical courses of this intoxication suggest that the utility of EGDS to remove tablets should be considered in selected cases of drug poisoning.
\end{abstract}

\section{Case Report}

We describe a case of a 83-years-old woman attended to the Emergency Department after voluntary ingestion of referred 28 tablets of Oxycodone $10 \mathrm{mg}$ slow release for suicide purpose. Outof-hopital emergency system were activated 45 minutes after ingestion. The patient has a medical history of arterial hyperten-

Correspondence: Sossio Serra, Emergency Department, Maurizio Bufalini Hospital, viale Girotti, 286, 47522 Cesena (FC), Italy

E-mail: sossio.serra@gmail.com

Key words: Oxycodone; poisoning; gastric decontamination; EGDS.

Conflict of interest: No one. This work was not supported by any grant.

Availability of data and materials: All data underlying the findings are fully available.

Ethics approval and consent to participate: No ethical committee approval was required for this case report by the Department, because this article does not contain any studies with human partici-pants or animals. Informed consent was obtained from the patient included in this study.

Consent for publication: The patient gave her written consent to use her personal data for the publi-cation of this case report and any accompanying images.

Received for publication: 4 July 2020.

Accepted for publication: 15 September 2020.

This work is licensed under a Creative Commons Attribution 4.0 License (by-nc 4.0).

${ }^{\circ}$ Copyright: the Author(s), 2021

Licensee PAGEPress, Italy

Emergency Care Journal 2021; 17:9226

doi:10.4081/ecj.2021.9226 sion, hypercholesterolemia, pacemaker implantation for seno-atrial disease, diffuse arthrosis and osteoporosis with recent rotule fracture leading a partial loss of autonomy. Medical therapy was bisoprolol $2.5 \mathrm{mg}$, atorvastatine $20 \mathrm{mg}$, canrenone $25 \mathrm{mg}$. When emergency medical service arrived, the patient was drowsed, but awake if verbal stimulated Glasgow Coma Scale (GCS) 14. Bilateral myotic pupils. Blood Pressure was 140/70 $\mathrm{mmHg}$, Heart Rate 90 bpm, Peripheral O2 Saturation $96 \%$ in room air with transient bradypnea. After Naloxone $0.4 \mathrm{mg}$ intravenous (IV) administration to reverse respiratory depression, we assisted to retrieval of normal consciousness and breathing. During the transfer to the hospital vomiting occurred and nasogastric tube has been placed. No pills traces have been detected by gastric lavage from nasogastric tube. In-hospital first evaluation documented drowsiness and transient bradypnea. Clinical head-to-toe evaluation showed only myotic pupils. Normal blood pressure and heart rate were reported. Second dose of Naloxone $0.4 \mathrm{mg}$ IV have been administrated followed by a third intramuscular dose with rapid consciousness improvement and interruption of the bradypnea. Considering the GCS 15, time of ingestion (more or less one hour), and the compliance of the patient, gastric lavage with 40 French orogastric tube has been performed. Only few tablets were retrieved. Intravenous continuous Naloxone $0.025 \mathrm{mg} / \mathrm{kg} / \mathrm{h}$ infusion was started. Considering the high dose of Oxycodone ingested and the slow release pharmacological cinesis, according with the Poisoing Center and endoscopy specialist, we decided to perform EGDS two hours after ingestion. The EGDS reported regular esophagus, cardias incontinence for hiatal hernia, hyperemic gastric mucosa with erosive spots, normal duodenum mucosa. Near the gastric bottom 14 pills were highlighted, another pill was found on duodenal bulb level. Using a small net and in multiple steps approach, all pills were removed (Figure 1 and 2). No bezoar was found. After the procedure the patient appeared with GCS 15 and myosis disappeared. Normal cardiopulmonary findings have been documented. Oral activated charcoal $50 \mathrm{mg}$ was administered followed by 30 mg of magnesium sulphate (which had not been administered previously considering the performance of endoscopic procedure) to prevent the possible post pyloric absorbition. After one hour, IV continuous Naloxone infusion was stopped and the patient was admitted to sub-intensive ward for observation because the high risk of delayed or secondary opioid peak. Naloxone administration was not necessary anymore. Only a qualitative drug essay was performed. No substance abused were demonstrated other than opioids. Clinical course was regular and without complications, on day 3 the patient was discharged after psychiatric evaluation, prescribing antidepressant therapy.

\section{Discussion}

Gastric decontamination is the main approach to the patient with incongruous pills oral intake. Official guidelines are missing 
but we have a number of position papers and statements made by the most important international scientific societies, such as the American Accademy of Clinical Toxicology (AACT) and the European Association of Poison Centers and Clinical Toxologist (EAPCCT) providing the practical approach to this situation. Gastric decontamination techniques (gastric lavage, activated charcoal and emetics) have specific indications and contraindications, and AACT/EAPCCT statements do not recommend their routinely application. ${ }^{1}$ Clinical studies showed that there is high variability in relation of the amount of substances that may be removed by gastric decontamination, depending on several factors including the characteristics of the substance, its formulation (for example compounds of prolonged release), the time of ingestion and the dose taken. Pharmaceutical agent factors, both intrinsic (tablet size, persistance, adhesiveness, viscosity) and extrinsic (anti-

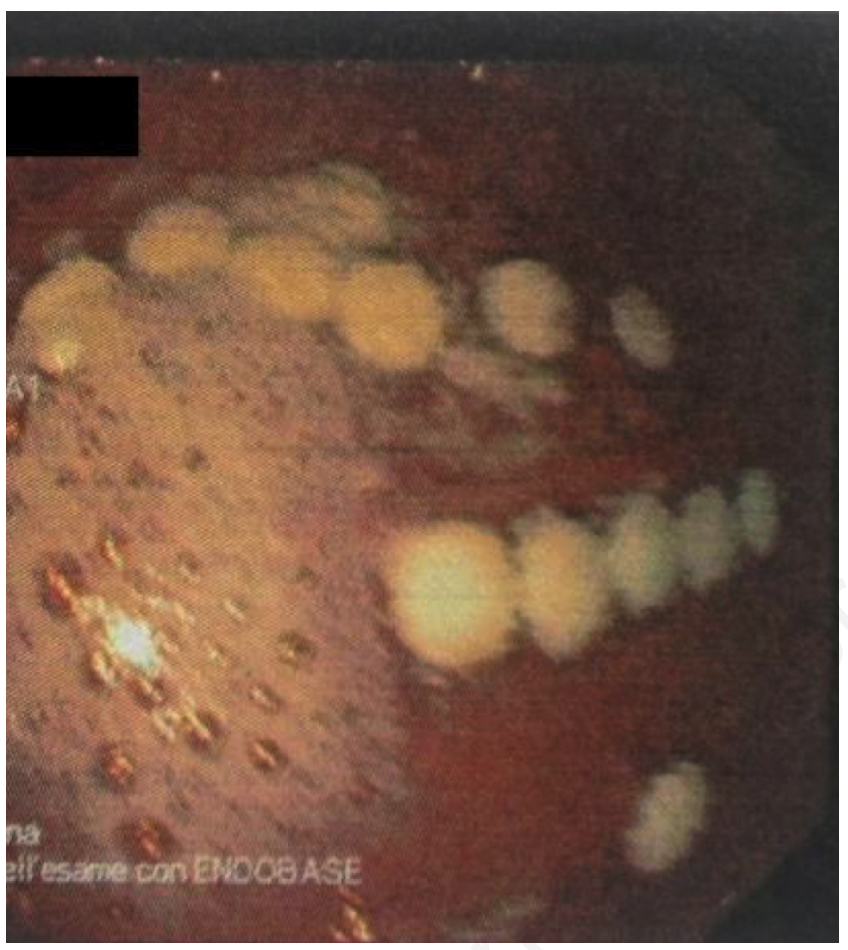

Figure 1. Oxicodone tablets seen in gastroscopy.

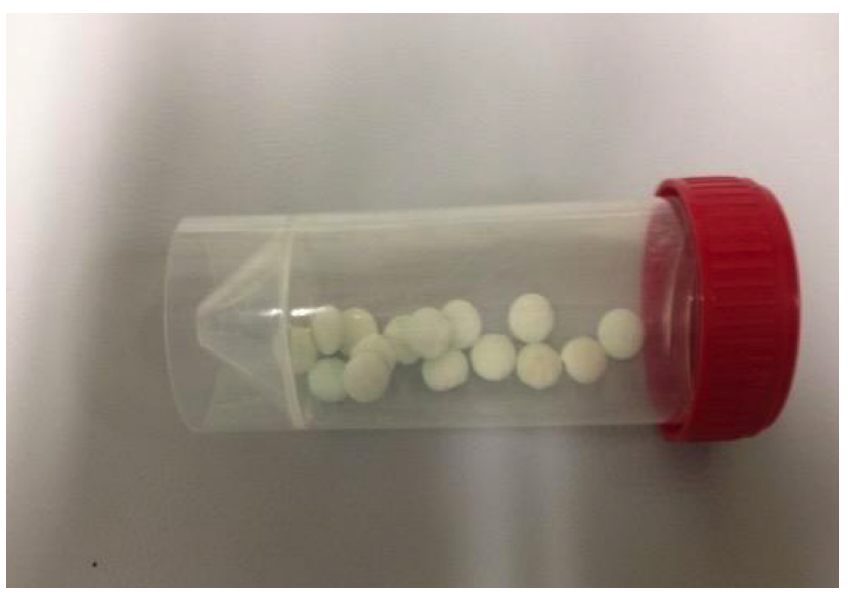

Figure 2. Oxycodone tablets removed by gastroscopy. cholinergic or opiate effects, ability to cause pylorospasm or GI tract atony) should also be considered. ${ }^{2}$ Agglomerates of tablets (bezoar) can represent an obstacle to effectiveness of gastric decontamination. As recently reported by Hoegberg et al., when some components are present in slow release formulation drugs (eg. hypromellose or alginate or acrylate), clinicians should be alert for risk of pharmacobezoar formation. Oxicodone $10 \mathrm{mg}$ SR contain hypromellose; this aspect could be the main reason why this drug forms bezoars.

Moreover, tablets can strictly adhere to the gastric wall mucosa leading to ineffectiveness of traditional decontamination strategies. In these specific cases, direct postero-anterior abdomen radiography may help to identify macro-aggregates of tablets. ${ }^{3}$ Because of that sometimes we need to consider the possibility to perform EGDS to remove tablets. There are no specific or standardized indications to perform EGDS in intoxicated patient and how to treat pharmacobezoars. Examples of forced elimination of pharmacobezoars have been reported by several different procedures either by breakage using carbonated beverage as ingestion and/or intrabezoar injection or removal by endoscopic capture with or without prior fragmentation, rectal removal, or surgery. 3,4

Saeki et al. described a case of 50 pills slow-release Theophylline tablets ingestion. ${ }^{5}$ Pills aggregation was reported performing abdominal radiography but gastric lavage was useless to remove the bezoar. The EGDS performed 3 hours after ingestion removed 31 tablets. Djogovic et al. described a voluntary Venlafaxine ingestion that lead to bezoar removal by EGDS. ${ }^{6}$ Hojer and Personne reported other 2 cases of pills removal by EGDS, in one case the procedure has been performed after 5 hour of Chlorimipramine ingestion. ${ }^{7}$ Schwerk et al. reported a suicidal attempt by ingestion of Ethylefrine removed by EGDS after a failed attempt with gastric lavage. ${ }^{8}$ All author above agree about EGDS indication only after a failed attempt of the classical gastric decontamination approach. The clinical case we reported follows the experience of the authors above, leading the EGDS as a rescue therapy when classical gastric decontamination fails thought intoxication by drugs with long release formulations or dangerous for life. Every patient with massive pills ingestion needs a specific evaluation and may request a multidisciplinary approach.

\section{Conclusions}

Despite spontaneous emesis and gastric lavage performed in Emergency Department we did not detect any drug traces, and the EGDS made two hours after ingestion removed several tablets, contributing decisively to resolve Oxycodone overdose. There was a rapid resolution of intoxication symptoms after drug removal and the administration of Naloxone has no longer been necessary. In the case of massive acute overdoses, worsening clinical condition or rising serum drug concentrations after aggressive gastric decontamination should raise the possibility of a pharmacobezoar.

\section{References}

1. Buckley NA, Eddleston M. The revised position papers on gastric decontamination. Clin Toxicol (Phila) 2005;43:129-30.

2. Simpson SE. Pharmacobezoars described and demystified. Clin Toxicol (Phila) 2011;49:72-89.

3. Hoegberg LCG, Refsgaard F, Pedersen SH et al. Potential pharmacobezoar formation of large size extended-release 
tablets and their dissolution - an in vitro study. Clin Toxicol (Phila) 2019;57:271-81.

4. Lapostolle F, Finot MA, Adnet F, et al. Radiopacity of clomipramine conglomerations and unsuc-cessful endoscopy: report of 4 cases. J Toxicol Clin Toxicol 2000;38:477-82.

5. Saeki S, Shimoda T, Sakai H, et al. Successful treatment of theophylline toxicity by upper gastroin-testinal endoscopy. Clin Toxicol (Phila) 2007;45:735.
6. Djogovic D, Hudson D, Jacka M. Gastric bezoar following venlafaxine overdose. Clin Toxicol 2008;46:317-9.

7. Höjer J, Personne M. Endoscopic removal of slow release clomipramine bezoars in two cases of acute poisoning. Clin Toxicol (Phila) 2008;46:317-9.

8. Schwerk C, Schulz M, Schwerk et al. Etilefrinhydrochloride tablet ingestion: successful therapy by endoscopic removal of tablet conglomerate. Klin Padiatr 2009;221:93-6. 